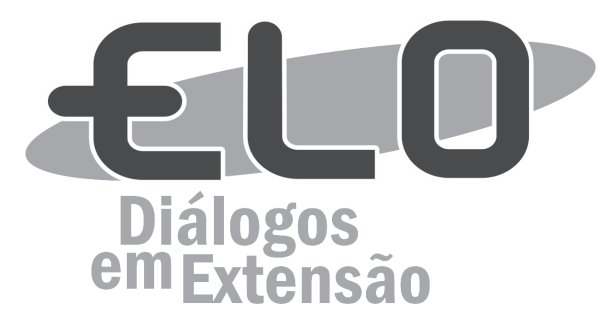

\title{
Diálogos entre agroecologia e educação popular: práxis e extensão
}

Renata Evangelista de Oliveira ${ }^{1}$; Valéria Oliveira de Vasconcelos ${ }^{2}$

\begin{abstract}
Resumo: O presente trabalho trata da sistematização das atividades decorridas de uma ACIEPE (Atividade Curricular de Integração Ensino, Pesquisa e Extensão), realizada na Universidade Federal de São Carlos/ Campus Araras. Buscamos apresentar as principais premissas que serviram de alicerce para as ações realizadas, articulando pontos convergentes entre a Educação Popular e a Agroecologia, apontando caminhos, ações e práticas comuns. O intuito foi o de propor reflexões que fomentassem futuras propostas de formação, articulação e vivências em extensão voltadas a distintas práxis educativas transformadoras.
\end{abstract}

Palavras-chave: Educação Popular. Agroecologia. Extensão. Formação universitária.

Área Temática: Educação, Agroecologia.

\section{Dialogues betweeenagroecology and popular education: praxis and extension}

Abstract: This article deals with the systematization of activities elapsed from a ACIEPE (Curricular Activity Integrating Education, Research and Extension) held at the Federal University of São Carlos/ Campus Araras. We present the main assumptions that served as the foundation for the actions taken by, articulating converging points between Popular Education and Agroecology, pointing out the ways, actions and common practices. The aim was to propose reflections that could support future educational opportunities, articulations and experiences aimed at different educational transformative praxis.

Keywords: Popular Education. Agroecology. Extension. University education.

\section{Diálogos entre laagroecologia y laeducación popular: práxis y extensión}

Resumen: Este artículo trata de lasistematización de lasactividadestranscorridas enuna ACIEPE (Actividad Curricular de IntegraciónEducación, Investigación y Extensión), celebrada enlaUniversidad Federal de São Carlos/Campus Araras. Buscamos presentar lasprincipaleshipótesis que sirvieron de base para lasacciones tomadas por laarticulación de puntos convergentes entre Educación Popular y Agroecología, señalandolos roles, acciones y prácticascomunes. El objetivo fueproponer reflexiones que podrían apoyar las propuestas futuras de formación, articulación y experiencias destinadas a diferentes praxis educativas transformadoras.

Palabras clave: Educación Popular. Agroecología. Extensión. Formación universitaria.

${ }^{1}$ Professora doutora em Ciência Florestal pela Universidade Estadual Paulista. Docente do Bacharelado em Agroecologia da Universidade Federal de São Carlos (UFSCar). UFSCar. Centro de Ciências Agrárias. Rod. Anhanguera, km 174. CP 153. Cep 13.600-970. Araras/SP. Email: reolivei@cca.ufscar.br. Telefone: 1935432888.

${ }^{2}$ Professora Doutora pela Universidade Federal de São Carlos/Universidade de Salamanca. Docente do Programa de Mestrado em Educação do Centro Universitário Salesiano de São Paulo (UNISAL). E-mail: valvas2013@gmail.com. 


\section{Preparando o terreno - primeiras palavras}

O simples da vida parece ser tão simples que, por simples ser, nada simples resulta...

A intrínseca relação entre Ensino, Pesquisa e Extensão é uma das ações mais propaladas em Instituições de Ensino Superior (IES) e, por esse motivo, muitas são as propostas que visam concretizar essa desejada inter-relação.

Segundo a Pró-reitoria de Extensão da UFSCar,

As Atividades Curriculares de Integração Ensino, Pesquisa e Extensão (ACIEPEs) são uma experiência educativa, cultural e científica que, articulando o Ensino, a Pesquisa e a Extensão e envolvendo professores, técnicos e alunos da UFSCar, procura viabilizar e estimular o seu relacionamento com diferentes segmentos da sociedade. Como pesquisa e extensão, constitui-se em uma forma de diálogo com estes segmentos sociais para construir e reconstruir conhecimento sobre a realidade, de forma compartilhada, visando à descoberta e experimentação de alternativas de solução e encaminhamento de problemas. Como ensino, constitui-se na possibilidade de reconhecimento de outros espaços, para além das salas de aula e laboratórios, como locais privilegiados de aprendizagem significativa onde o conhecimento desenvolvido ganha concretude e objetividade (UFSCar, 2016).

Entre os muitos objetivos dessas atividades curriculares estão: intensificar a aproximação da universidade com a sociedade; ensejar a experimentação de alternativas metodológicas de trabalho comunitário e de ensino e favorecer o desenvolvimento de uma atitude tanto questionadora como proativa diante dos desafios e limites impostos pela nossa realidade social (UFSCar, 2016).

Nessa perspectiva, foi proposta uma ACIEPE pelas autoras desse artigo que, por conta das respectivas atuações profissionais, buscaram articular duas áreas do conhecimento que historicamente alimentam-se das mesmas fontes e, por conseguinte, poderiam apontar possibilidades mais orgânicas de formação e atuação profissional, quais sejam: A Educação Popular (EP) e a Agroecologia (AGEA).

Essa atividade curricular envolve aporte teórico conceitual nessas duas áreas, referencial esse plenamente condizente com o Projeto Pedagógico do Curso (PPC) de Bacharelado em Agroecologia (alvo da ACIEPE). O PPC (UFSCAR, 2009) aponta uma relação permanente entre instituição de ensino, educandos e comunidade e articulação dos saberes acadêmicos e saberes populares/empíricos de sujeitos locais. A ACIEPE prevê uma perspectiva interdisciplinar e atende ao desafio de se associar teoria e prática. Proporciona, por meio do público-alvo pretendido e da proposição de elaboração de intervenção pelos educandos, que a realidade, as situações próximas das pessoas, dos educandos, seus contextos socioeconômicos e culturais e formas de organização sejam pontos de partida para a construção do conhecimento.

\section{Aportes teóricos:}

De acordo com Alfonso Torres Carrillo (2008), a Educação Popular é uma corrente pedagógica legitimamente latino-americana e seu conceito vai variar segundo as implicações e determinações políticas das quais partem seus autores. Diversas definições remetem a momentos específicos e a diferentes olhares entre os agentes educativos. No entanto, o autor colombiano aponta para um "núcleo comum" de elementos constitutivos, que podem ser mais ou menos explícitos ou implícitos, e que possibilitaria defini-la, quais sejam:

1. Uma leitura crítica da ordem social vigente e um questionamento do papel integrador que a educação formal vem representando;

2. Uma intencionalidade política emancipadora ante a ordem social imperante;

3. O propósito de contribuir ao fortalecimento dos setores dominados como sujeitos históricos, capazes de protagonizar a transformação social. 
4. Uma convicção que desde a educação é possível contribuir a alcançar essa intencionalidade, atuando sobre a subjetividade popular.

5. Um afã por gerar e empregar metodologias educativas dialógicas, participativas e ativas (TORRES CARRILLO, 2008, p. 19 - tradução nossa).

Para Brandão (1984) a Educação Popular é uma práxis educativa que tem como premissa fundamental a promoção de uma "educação libertadora" e será aqui entendida, conforme apontam Vasconcelos e Oliveira (2009), como um processo de humanização, um ato político, de conhecimento e de criação, que ocorre no diálogo entre seres humanos, sujeitos de sua vida e que, solidariamente, fazem e refazem o mundo.

As autoras apontam ainda que, ao se referirem à Educação Popular, estão reafirmando uma forma de "educação com as classes populares, com elas compromissada e com elas realizada, mediante o diálogo" (VASCONCELOS \& OLIVEIRA, 2009, p.136).

Além disso, complementando o pensamento dos autores apresentados, Paludo $(2015$, p.220) afirma que a:

[...] Concepção de Educação Popular (EP) como campo de conhecimento e como prática educativa se constituiu em exercício permanente de crítica ao sistema societário vigente, assim como de contra hegemonia ao padrão de sociabilidade por ele difundida. Construída nos processos de luta e resistência das classes populares, é formulada e vivida, na América Latina, enquanto uma concepção educativa que vincula explicitamente a educação e a política, na busca de contribuir para a construção de processos de resistência e para a emancipação humana, o que requer uma ordem societária que não seja a regida pelo capital.

Nessa perspectiva, fica clara a convergência entre a Agroecologia e a Educação Popular. Ambas trazem em suas bases fundamentais a oposição à alienação e à domesticação, a valorização de saberes populares e tradicionais, a busca pela emancipação e construção de autonomia para transformação da realidade. Pautam-se e dialogam com movimentos sociais e populares, propõem práticas mais humanizadoras baseadas em relações dialógicas e horizontais entre seus atores.

Para Altieri (1998, p. 23), a Agroecologia trata:

[...] de uma nova abordagem que integra os princípios agronômicos, ecológicos e socioeconômicos à compreensão e avaliação do efeito das tecnologias sobre os sistemas agrícolas e a sociedade como um todo. [...] utiliza os agroecossistemas como unidade de estudo [...] incluindo dimensões ecológicas, sociais e culturais.

A Agroecologia pode ser entendida como ciência, como prática e, ainda, como movimento, já que pressupõe formas de ação social coletivas e a articulação de atores sociais como forma de resistência ao modelo hegemônico estabelecido para a agricultura (LO SARDO \& FIGUEIREDO, 2015).

Isto posto, perguntamo-nos: $\mathrm{O}$ que há de inédito entre juntar teorias convergentes, quando as premissas de uma se alimentam das de outra? O que há de inédito em trazer o saber popular para o diálogo com os saberes construídos na universidade, quando os de uma bebem nas fontes dos saberes do outro? O que há de inédito em fomentar o diálogo entre horizontais epistemologias?

A obviedade dos caminhos não elimina seu ineditismo, uma vez que o trilhar será ressignificado em cada novo percurso. Não por acaso Paulo Freire (2001) foi considerado por ele mesmo um andarilho do óbvio.

\section{Relato sobre nossa experiência: principais atores e autores, atividades realizadas, reflexões...}

A ACIEPE de que trata esse relato foi oferecida duas vezes, em dois momentos: em semestres letivos de 2015 e de 2016, envolvendo grupos distintos de educandos. Entretanto, não os enxergamos em separado, e sim como um processo único, construído a partir de múltiplos encontros. 
O processo de criação e realização da ACIEPE, a partir de encontros periódicos, teve como linha mestra o desejo (e o desafio) de trazer a Educação Popular (EP) para os espaços formais do ensino superior e buscar em suas bases epistemológicas pautas vinculadas à Agroecologia (AGEA) e à extensão universitária no meio rural e urbano, integrando múltiplas áreas de conhecimento.

Para isso, estabelecemos uma relação não meramente interinstitucional (com o oferecimento da atividade por duas docentes, em duas IES, de áreas distintas: na UFSCar, do curso de Bacharelado em Agroecologia, na UNISAL, do programa de Mestrado em Educação Sociocomunitária), mas multi e interdisciplinar, em que a relação dialógica entre AGEA e EP pudesse ser experimentada por meio da troca entre múltiplos saberes. Cabe aqui citar a interdisciplinaridade na visão de Freire, presente como verbete no Dicionário Paulo Freire organizado por Strecket al. (2016), estabelecida:

Como requisito para uma visão da realidade nas perspectivas da unidade e da totalidade do real. [...] Ao processo analítico de cindir o real através de parcialidades disciplinares, deve-se seguir a retotalização transdisciplinar, mediante um processo epistemológico interdisciplinar (ANDREOLA, 2016, p. 229).

Quisemos trazer para reflexão, proposição de intervenções sociais e atividades de extensão, a multidisciplinaridade dentro do olhar poliocular aprofundado por Edgar Morin. Para o autor, "tudo o que é humano é ao mesmo tempo sociológico, econômico, histórico, demográfico. É importante que esses aspectos não sejam separados, mas concorram para uma visão poliocular" (MORIN, 1983. Em: WHITAKER \& FIAMENGUE, 2002, p. 21).

Esse olhar emergiu da diversidade na formação e atuação profissional dos participantes e, principalmente, da multiplicidade de histórias de vida, de saberes e de demandas advindas desse convívio. O grupo foi formado por alunos de graduação e pós-graduação em agroecologia, pedagogia, biotecnologia e por profissionais atuando nas áreas de educação, engenharias, direito e eletrônica.

A multidisciplinaridade foi ampliada a partir de encontros pontuais em que propusemos uma formação vinculada a atividades de outros grupos, sendo um com um grupo de práticos e estudiosos em Permacultura; outro com o Núcleo de Apoio a Populações Ribeirinhas da Amazônia (NAPRA) e um último junto a alunos do Mestrado em Educação da UNISAL. O intuito foi dialogar sobre distintas realidades, buscas, conceitos e ideologias, e refletir sobre a Educação Popular em nossa atuação cotidiana.

Entram aqui o multiculturalismo, o respeito à diferença alicerçado na dialogicidade, a unidade na diversidade, a práxis, a participação, as relações e práticas humanizadoras, além da busca por transformação da realidade, entre outras premissas profundamente atreladas à obra de Paulo Freire e retomadas por nós, em nossas falas e práticas, no desenrolar das atividades de extensão.

Os encontros foram realizados em distintos espaços de formação, abrangendo um conjunto de lugares e cenários também múltiplos: no Campus da UFSCar (em Araras/SP), no Sítio da Rosa dos Ventos (em Pocinhos do Rio Verde/MG), no Sítio Manacá (em São Carlos/SP). A Rosa dos Ventos é uma casa de acolhida criada pelo professor Carlos Rodrigues Brandão há quase vinte anos, como um espaço de aprendizado, experiências, ações, encontros e celebrações pautadas na vivência e convivência solidárias. Entendemos o Sítio Manacá como um "campus avançado" da Rosa dos Ventos, em decorrência de um processo que já vem ocorrendo há muitos anos, de complementaridade e integração das ações desenvolvidas nesses dois lugares. Ambos são também espaços de resistência e de luta pela preservação das paisagens rurais em que se inserem e possibilitaram o encontro com diferentes cenários, do ponto de vista ecológico/geográfico, agrícola e ambiental.

As premissas fundamentais difundidas nesses e por esses espaços são, entre outras: a solidariedade, a partilha, a alimentação e vida saudáveis, a educação ambiental, a economia solidária e a Educação Popular.

Para cada encontro foram definidos de dois a quatro textos como leituras prévias, que foram lidos pelos alunos. A partir desses textos, trabalhamos seu conteúdo com relatos de experiências, tertúlias literárias dialógicas (FLECHA \& MELLO, 2005), rodas de conversa, dinâmicas de grupo, debates, relatos verbais e leitura e produção de textos e apontamentos. 
Essas atividades foram desenvolvidas no intuito de vivenciar diferentes estratégias de ensinoaprendizagem que podem ser utilizadas e partilhadas nas mais diversas atividades cotidianas de ensino, pesquisa e extensão.

Esse aporte teórico (ministrado de forma não convencional e em espaços não formais) foi sempre relacionado à proposição, pelos alunos, de intervenções de extensão e práticas educativas, e foi estimulada, sempre, a reflexão sobre a inserção da educação popular e seus pressupostos à prática da Agroecologia e às ações junto a educadores, agricultores e extensionistas.

A qualidade da participação dos distintos atores envolvidos na ACIEPE merece igual destaque, uma vez que em processos pautados na Educação Popular, a cooperação e a construção conjunta de saberes possibilitam aproximações interpessoais que podem desvelar metas comuns. Dessa forma, realizamos mutirões para construção de cercas, limpeza de espaços de convivência, preparo de refeições, observações de espaços rurais, a partir dos quais tivemos a oportunidade de trocar informações e concepções de mundo, numa atitude dialógica e de respeito mútuo com notórios ganhos individuais e coletivos. Como afirma Vasconcelos (2002, p.176): “A participação, portanto, deve ser aproveitada para a mobilização da comunidade em direção a ações concretas; não importa somente a presença das pessoas, mas sim o nível de comprometimento que se alcança com o trabalho participativo".

Todas as ações decorrentes da ACIEPE proposta tiveram como substrato a obra de Paulo Freire e de outros tantos autores que discutem a Educação Popular e a Agroecologia na América Latina. Entre eles destacamos: Alfonso Torres Carrillo, Alfonso Ibañez, Carlos Rodrigues Brandão, Enrique Dussel, Fabian Cabaluz Ducasse, Francisco Roberto Caporal, Marco Raúl Mejía, Miguel Altieri e Roseli Salete Caldart.

Esse referencial, para além de contribuir para o aprofundamento teórico e ampliação de visão de mundo, deu suporte para uma intrínseca relação entre teoria e prática, o que Freire denomina práxis.

Para Vásquez (2007), a relação entre teoria e prática implica um constante vaivém entre esses dois planos. A atividade prática se sujeita, conforma-se à teoria, do mesmo modo que a teoria se modifica em função das exigências e necessidades do próprio real. Para esse autor, a práxis não é apenas atividade social transformadora, no sentido da transformação da natureza, da criação de objetos, de instrumentos, de tecnologias; é atividade transformadora também com relação ao próprio ser humano que, na mesma medida em que atua sobre a natureza, transformando-a, produz e transforma a si mesmo.

Nesse sentido, consideramos e tomamos a práxis como fundamento da prática educativa a sustentar toda formação em Extensão Universitária que se pretende crítica e transformadora.

\section{Palavras finais}

Nós consideramos que, quando se fala em Extensão Universitária, em geral o discurso é progressista, porém, as práticas de formação são convencionais, para não dizer retrógradas. Portanto, propusemos e desenvolvemos atividades buscando, em uma atividade de ensino universitário, um exercício da práxis como alicerce de todo um processo de ensino-aprendizagem.

Os aprendizados que se revelaram no decurso da ACIEPE (a partir de relatos dos nossos alunos), sugerem que diálogo, participação e respeito aos diversos saberes são pressupostos que parecem óbvios, porém não são usuais nas práticas de formação em extensão e no ensino superior.

Entendemos, portanto, a Educação Popular como uma práxis educativa transformadora que pode, concretamente, contribuir para uma ressignificação da Extensão Universitária.

\section{Fonte de financiamento}

A realização da ACIEPE contou com apoio financeiro da Pró-Reitoria de Extensão da Universidade Federal de São Carlos.

\section{Agradecimento}

Ao professor Carlos Rodrigues Brandão, parceiro afetivo, mentor e inspirador deste projeto e de muitos outros, em construção.

Aos alunos participantes da ACIEPE, que tornaram possível sua realização. 


\section{Referências Bibliográficas}

ALTIERI, Miguel. Agroecologia: a dinâmica produtiva da agricultura sustentável. Porto Alegre, Editora UFGRS: 1998.

ANDREOLA, Balduíno. Interdisciplinaridade. In: STRECK, Danilo; REDIN, Euclides; ZITKOSKI Jaime José. (Orgs). Dicionário Paulo Freire. São Paulo, Editora Autêntica: 2016.

BRANDÃO, Carlos Rodrigues. A Questão Política da Educação Popular. São Paulo, Editora Brasiliense: 1984.

FLECHA, Ramón; MELLO, Roseli Rodrigues. Tertúlias literárias dialógicas: compartilhando histórias. Presente! Revista de Educação. n. 48, p. 29-33, 2005.

FREIRE, Paulo. Pedagogia dos sonhos possíveis. São Paulo: Editora UNESP, 2001.

LO SARDO, Paola Maia; FIGUEIREDO, Rodolfo Antonio. A construção do campo da Agroecologia e sua relação com o desenvolvimento rural. Interthesis. v.12, n. 1, p. 337-360, 2015.

PALUDO, Conceição. Educação Popular como resistência e emancipação humana. Cadernos Cedes. v.35, n.96, p. 219-238, 2015.

TORRES CARRILlO, A. La Educación Popular. Trayectoria y actualidad. Bogotá, El Buho Editorial: 2008.

UNIVERSIDADE FEDERAL DE SÃO CARLOS, Pró Reitoria de Extensão. ACIEPES. Disponível em: <http://www.proex.ufscar.br/site/menu-1/aciepes>. Acesso em: 30 maio 2016.

UNIVERSIDADE FEDERAL DE SÃO CARLOS, Conselho de Coordenação do Curso de Bacharelado em Agroecologia. Projeto pedagógico do Curso de Bacharelado em Agroecologia. Disponível em: <http://www.cca.ufscar.br/agroecologia/>. Acesso em: 15 jul. 2016.

VASCONCELOS, Valéria Oliveira de; OLIVEIRA, Maria Waldenez de. Educação Popular: uma história, um que-fazer. Educação Unisinos. v.13, n.2, p. 135-146: 2009.

VASCONCELOS, Valéria Oliveira de. Bebendo em uma fonte de Água Fresca.Caminhos para a Formação de Agentes Comunitários. Tese de doutorado. Universidade Federal de São Carlos. Centro de Educação e Ciências Humanas. Programa de Pós-Graduação em Educação. São Carlos/SP, Agosto 2002.

VÁZQUEZ, Adolfo Sanchez. Filosofia da Práxis.São Paulo, Expressão Popular: 2007.

WHITAKER, Dulce C.A. e FIAMENGUE, Elis C. Ciência e Ideologia: as armadilhas do preconceito. In: WHITAKER, Dulce. Sociologia Rural: questões metodológicas emergentes. Presidente Wenceslau: Letras à Margem, 2002.

Recebido para publicação 6/5/2016 em e aprovado em 20/7/2016. 